\title{
A Study on the Role of Facebook in E-Learning
}

\author{
Sana Khan ${ }^{\mathrm{a}}$, Sheikh Tahir Bakhsh ${ }^{\mathrm{b}}$ \\ ${ }^{a}$ COMSATS Institute of Information Technology, Virtual Campus, 44000 Islamabad, Pakistan \\ ${ }^{b}$ Computer Skills Unit, Faculty of Computing and Information Technology, King Abdulaziz University, 21589 \\ Jeddah, Makkah, Saudi Arabia
}

\begin{abstract}
This study basically investigates the current motivation to use Facebook as a supportive tool for e-learning in a higher education institute of Pakistan. Faculty interviews are conducted to collect the opinions about Facebook as learning and teaching tool. Also statistics on a subject based Facebook page and a group designed for undergraduate students are presented. It has been concluded that Facebook can play its role to facilitate elearning as more than a social networking website. It is analysed that participation and engagement of students on Facebook page and group is quite optimistic to use it as a supportive tool in future. Results can also help learners and teachers to understand the importance and effects of using social networking website for e-learning.
\end{abstract}

Index Terms: E-Learning, Social networking, Facebook, Higher education.

(C) 2015 Published by MECS Publisher. Selection and/or peer review under responsibility of the Research Association of Modern Education and Computer Science.

\section{Introduction}

With the rapid advancement of information technology, E-learning has emerged as an important tool to provide facilitation for education in most of the institutions all over the world. Students' life is greatly influenced by online social networks today. Online social interactions have the ability to influence students' social aspects and learning outcomes. E-learning allows web and computer based learning and offers a wide range of facilities to the learners by the use of information and communication technology [1]. In the simplest terms, instructions delivered via all electronic media are what we call e-learning [1,2]. E-Learning System allows group interaction and communication for the geographically distributed users without the constraint of time and space through computer supported collaborative technologies [3]. In other words, E-learning is the online delivery of information for learning, training and knowledge management, beneficial for students and institutions making use of IT and Internet to support the learning process [2, 4]. E-learning has been defined in the number of ways with all emphasized on the use of internet and information technology for instructions and

\footnotetext{
* Corresponding author. Tel.: +92 51 9262236-38;
}

E-mail address: sanakhanre@yahoo.com 
learning [2].

In the context of education use of social networking is considered to be a good idea, as it allows establishment of contacts, relationships, information sharing, and self-initiated learning [5]. Social network utilities allow easy and quick interactions [28]. Online social networking has the direct impact on university students' learning outcomes, but also helps the students to gain social benefit from others and their settlement in the university culture [4]. In e-learning role of Social Networking Sites (SNS) is supportive and important [3, 6]. Social interactions with more capable peers enhance the learner's understanding [6]. Social Networking websites allow the learners to share information and interact, which in turn allow the individual participation and develop more interest toward learning. It has been proposed that with the growing popularity of SNS, the social and interactive nature of SNS could be exploited positively to play its role in successful learning by enhancing social communication and overall quality of interaction among faculty and students. Social networking technology can be used effectively as a tool to promote a culture of learning for a small group of users [7].

In this paper the interviews summary of the faculty members of a semi government e-learning institute has been presented. It investigates the integration of Facebook as a supportive tool in e-learning. Moreover the statistics of students' participation in a subject based Facebook page and group are also presented. Results show that Facebook can be used positively as a supportive tool for teaching and learning in an e-learning environment.

\section{Literature Survey}

Social networking has become very common in our society today [8 - 10, 29, 33, 34, 36]. With the use of social networking, the way of connecting with everyone in the world is now so easy [39]. Social networking allows the active participation in activities and service by sharing of contents, opinions, and supports the creation of groups according to specific needs of the participants $[8,36]$. Facebook has been considered as the most popular social networking website [12 - 17, 29, 35]. It is highly adapted SNS among college and university students $[17,18,35]$. Facebook can help students to improve their learning outcomes by achieving a high level of self-esteem, social acceptance and adaptation in university life [17, 23, 26, 27]. It has been used as course management software, allowing the learners to participate actively by producing information and instructor as a facilitator to create a helpful environment for active learning. Facebook provided a great opportunity to run a course in-person and online [28]. Student-to-student interactions have also shown positive effects on student success. These interactions between peers in a social networks, may lead to social learning [37]. The use of social networking sites among the teachers has also become common; the teachers in the colleges and universities can make use of social networking tools for disseminating knowledge to their students [38].

Another study proposed that Facebook has been widely adopted by the students and is one of the most popular social networking website that could help students in their educational communication and collaboration with faculty in the context of higher education [18]. Various studies have been conducted to explore the use of Facebook by students, faculty, and to predict future role of Facebook in the context of higher education [18, 30, 31]. It has been suggested that Facebook can positively impact a college student's life [19] by sharing the course related information between student to student and student to teachers. Facebook has been widely investigated as an instructional tool [9]. Facebook has also been used to encourage the EDB (Emotionally Disturbed Students) students in their routine matters, as more than a social networking tool. The findings of this study proved that it can be used more than a social networking website [12]. Other studies investigated the student's use of Facebook and similar technologies like that seems more than faculty to support classroom work. Faculty members are more interested in technologies such as email and reluctant to use this technology for instructional purposes [17, 18].

\section{Facebook and E-learning}


Lack of physical interaction still remains the real challenge in the success of e-learning [4] as there is a chance of deviation from the main objective due to lack of interaction, monitoring and control from teachers. It has been proved statistically that greater online interaction has a positive and significant impact on the performance of students studying via e-learning [20]. Facebook as a course supplement and a teaching tool has been discussed in literature [21]. Online social networking tools allows interaction, collaboration resource sharing and active participation [5], which e-learning is in the dire need of, to improve the learning outcomes. The need for integrating online social networks with e-learning has been investigated [3] plus interaction improvement and improvement in course content understanding has been investigated from the use of Facebook [5]. Proper use of Facebook can improve the learning process through communication, interaction, collaboration, and resource sharing [17]. Some studies focused on improving students' performance by using Facebook [24]. Other studies on the use of Facebook in education have shown the positive results in the context of online discussions, peer support, strengthening social relationships, learning performance, sharing resources and information [13]. It has been proposed that communication, collaboration, and resource/ material sharing have a significant and positive effect on educational use of Facebook [17]. Use of Facebook as a learning resource can promote collaborative and cooperative learning [25].

Another study evaluated the use of Facebook in the context of a course by students, Facebook as a collaborative technology and Facebook to develop an informal learning environment. It is concluded that in future Social Networking Sites like Facebook can be easily adapted to play a significant contribution in teaching and learning beyond the traditional classroom [7]. Traditional e-learning tools like LMS, Moodle, and blackboard provide valuable services for teaching and learning but lacks social connectivity that could be used positively by the students involved in the e-learning. It has been concluded that SNS can play a major role in elearning and significant results could be achieved by the proper guidance and training to the students [6]. Collaboration, communication, resource sharing, social influence and usefulness and ease of use are the major factors that can facilitate the use of SNS in e-learning. Facebook has been identified as the most popular SNS through the survey. Use of Facebook at University of Malaga has not only allowed useful multi-way interaction of teachers \& students, but also provided the opportunity to the students for active participation in the teaching -learning process [22]. Social networks' are getting much popularity for information and knowledge sharing among students as compared to traditional technologies like email and should be integrated in e-learning [32].

\section{Aim of Study}

It has been widely examined that young people spend most of their time on social networking websites. Online social media encourage learners to learn. Scope of this study is to determine whether Facebook being the most popular social networking website may facilitate e-learning on the basis of current motivation to use Facebook by students' and faculty. Students in online learning environment have a communication gap with their teachers and engage with them through learning management system or other tools. Integration of social networking website like Facebook can bring significant learning outcomes.

\section{Interviews Summary}

Total 20 interviews are conducted with faculty members who are teaching undergraduate and postgraduate courses in different departments. Key points of the interview responses are discussed in detail as below:

\section{In your opinion, what are the advantages, Facebook can offer for e-learning?}

Facebook will offer more interactive environment as compared to LMS. Percentage of interaction between student-student and student-faculty would definitely be increased. It's a good platform for collaboration discussion and knowledge sharing. Facebook will provide comfortable environment. Development of interest in specific course through healthy discussions and brain storming sessions is the major advantage. Competition 
development, motivation and grooming of inactive students through interactive posts, discussion ethics development with students and teacher, informal problem sharing regarding course are some other advantages mentioned by the faculty members. There is a chance of overall positive growth of teacher, students and institutions by proper use. Students will be able to absorb information more easily. A shy student can get the answer of many of his questions because of other students' comments, which he cannot usually make clear in formal learning environment.

\section{In your opinion, what are the disadvantages of using Facebook for e-learning?}

Level of control over discussions will be difficult to manage so students can be distracted easily from the main objective. Comments and expressions are visible to everyone. Some students can use it only for fun. Establishing a boundary for discussion can be difficult to handle. Student teacher relationship needs to be managed the same way as in classroom environment.

\section{If you are asked to use Facebook for a course in e-learning, how will you manage it?}

Creation of pages and closed group with discussion on course related topics and problems as a mandatory activity for active participation by all students. Sharing of course related material like useful links and resources plus interesting and interactive posts on different topics by teacher as well as students. There should be incentives and time limits for discussion on topic. Use of video lectures and video chat for the sake of interest is also important. Some faculty members recommended to make comments must for active participation. Facebook groups can be thought of as a virtual class room through which different students can share their ideas online with the teacher and other students. Different educational games can be developed to help students understand difficult concepts in an interesting way.

\section{What is your experience since you are using Facebook? Have you used it for educational purposes?}

Some faculty members were using Facebook only for social interactions. Some of them are using for information about scholarships and have joined groups related to their area of interests, and social discussions. Some faculty members have joined groups for help in their research work and research papers/articles download as well. So there is a mix trend of using Facebook for social as well as professional purposes.

\section{Are you aware of the role Facebook is currently playing in higher education through electronic learning?}

Faculty members mentioned about the Facebook pages and groups of different institutes but not specifically related to its role in e-learning.

\section{In future what role Facebook can play in higher education institutes offering electronic learning?}

Teacher can show more supportive role, especially in case of students feeling shy to interact through any other media. Teacher's personality and behavior could be positively utilized. Students' priorities could be determined. Extra learning activities could be promoted not specifically related to course outline. It is an open platform especially for e-learning as youth is spending most of its time on Facebook. Perception about Facebook as being a platform only for fun and social interactions needs to be changed. It has all the features which could establish a healthy learning environment. Checking emails take time but Facebook notifications especially through SMS is the most positive feature for instant communication. As the major issue faced by online students and teachers is the lack of communication, Facebook can better address this issue by keeping them in contact by offering services of groups, pages, discussions and group conversations. 
7. Please share your suggestions regarding the use of Facebook in e-learning.

Facebook should be utilized in E-learning for effective collaboration of students with teachers and with other students. Facebook can be used positively to increase e-learning productivity at the responsibility of teachers with rules and regulations. Facebook should be evolved more in case of e-learning, not the use of a single teacher/institute will make it effective, until it is approved officially by policy makers. Proper training of teachers to monitor the students at social media is the first requirement. Proper guidelines should be given for how to treat the students and carry over the page/group at Facebook in an e-learning scenario.

\section{Results and Analysis}

After the interviews, a page was designed for the undergraduate subject Database Systems. Here we are presenting the statistics only for the total activity of the FB page to determine whether these statistics could lay down the basis for exploiting the Facebook positively in future in an e-learning scenario.

\subsection{Facebook Page Statistics}

Activity on the page was started on Nov, 2013 and ended on January 30, 2014, approximately for 3 months followed by the few likes and comments till Feb 25 2014. Statistics of the Facebook page for this time span are as follows. Table 1 shows the statistics for total likes, percentage of students who joined and percentage of students who actually participated. Percentage of each type of post by the tutor is shown in Table 2. Table 3 shows the total reach in terms of percentage for each category of FB posts by the tutor. Total number of posts by students and type of posts with their percentage is shown in Table 4 . Finally total likes and comments for each type of posts by the tutor at the Facebook page are mentioned in Table 5.

Table 1. Overall Participation

\begin{tabular}{ll}
\hline Post statistics & Count \\
\hline Total Strength of the Class & 170 \\
Total Likes for the FB Page & 107 \\
$\%$ of the students who joined & $62 \%$ \\
$\%$ of the students who participated & $26 \%$ \\
\hline
\end{tabular}

Table 2. Percentage of Different Types of Post Shared by Tutor

\begin{tabular}{ll}
\hline Total No. of posts by the tutor & 52 \\
\hline Type of Post & Percentage \\
\hline Course / Content based & 46 \\
Motivational & 31 \\
Announcements & 13 \\
General Discussion & 10 \\
\hline
\end{tabular}

Table 3. Percentage of Total Reach

\begin{tabular}{ll}
\hline Type of Post & Reach in \% \\
\hline Course / Content based & 50 \\
Motivational & 30 \\
Announcement & 11 \\
General Discussion & 09 \\
\hline
\end{tabular}


Table 4. Statistics of Students' Posts

\begin{tabular}{ll}
\hline Total No. of posts by the Students & 54 \\
\hline Type of posts with percentage Count & \\
\hline Course related (Concepts, queries) & 52 \\
General & 02 \\
Percentage of students who posted & $08 \%$ \\
\hline
\end{tabular}

Table 5. Total Likes and Comments for Each Type of Post

\begin{tabular}{lll}
\hline Type of Post & Total Likes & Total Comments \\
\hline Course / Content based & 68 & 130 \\
Motivational & 72 & 71 \\
Announcement & 25 & 06 \\
General Discussion & 25 & 17
\end{tabular}

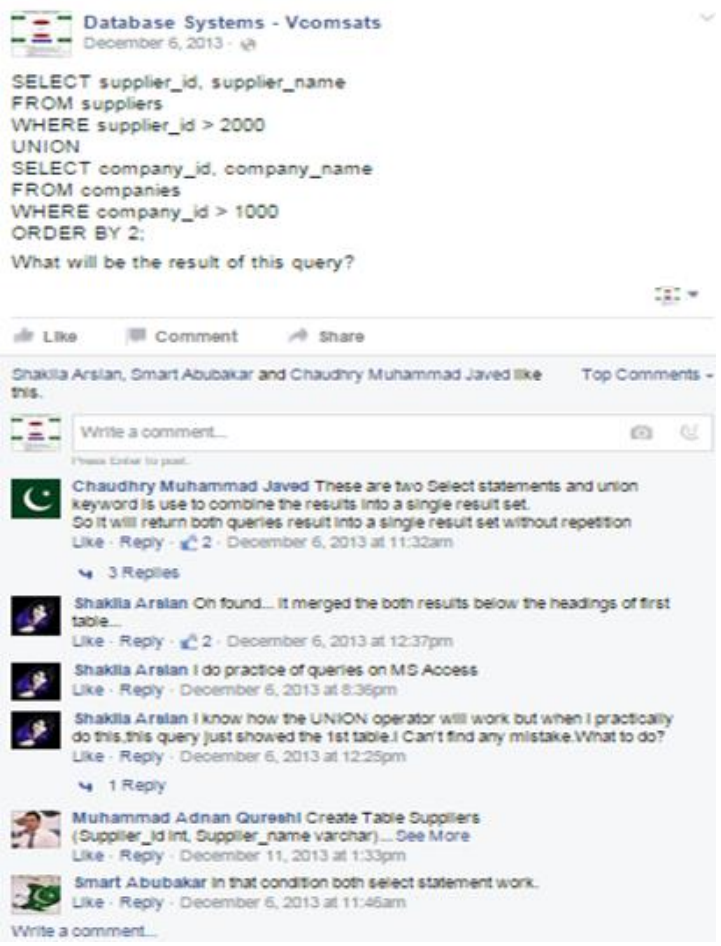

Fig. 1. (a) Example of Quiz by Code; (b) Example of Quiz by Text

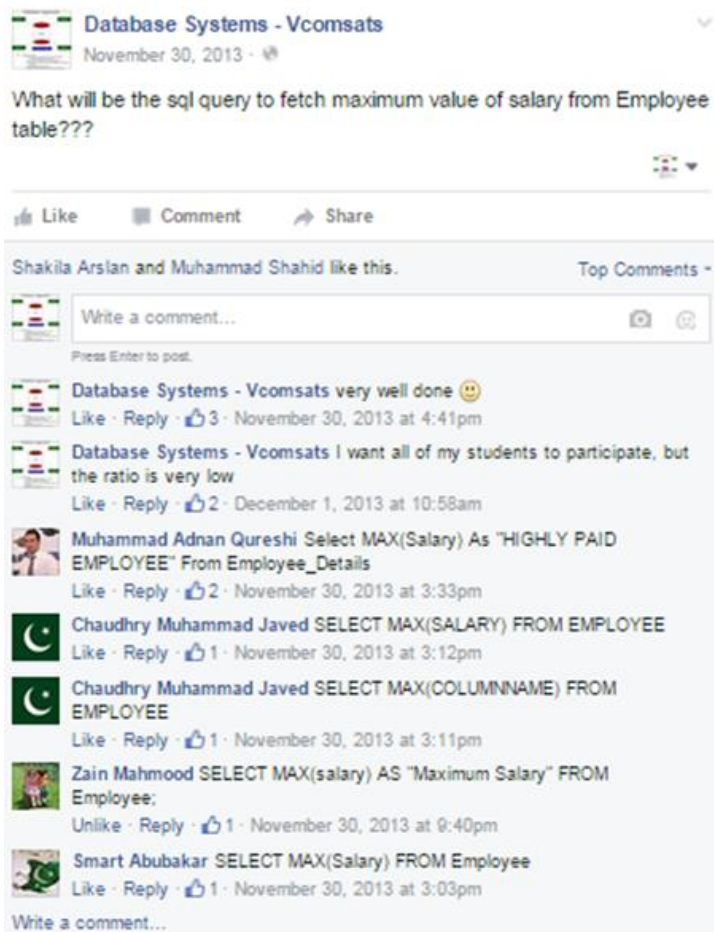

\subsection{Facebook Group Statistics}

A group was initiated for undergraduate subject "Introduction to Computer and Programming" on March 18 2015 for novice programmers. The objective to start this group was to provide students with a platform for productive and interactive discussions related to this course. Students were informed through email to join the group and add their class mates too. Group activities included discussion topics (course related and general discussion related to studies), daily quiz, course related queries, links and announcements. Students were 
motivated by posting the names of top students in quiz assignment and sessional exams. Necessary statistics related to the group are presented below. According to these statistics Facebook can be promoted as learning and teaching tool specifically in an e-learning environment.

Table 6. Key Statistics

\begin{tabular}{ll}
\hline Post statistics & Count \\
\hline Total Posts shared & 169 \\
Posts by Admin & 75 \\
Posts by Students & 95 \\
Total Likes & 524 \\
Total Comments & 1566 \\
Likes for Teacher's posts & 343 \\
Likes for Students' posts & 181 \\
Comments for Teacher's posts & 639 \\
Comments for students' posts & 927 \\
\hline
\end{tabular}

Table 7. Member Statistics

\begin{tabular}{ll}
\hline Member statistics & Count \\
\hline Total Members & 141 \\
Active Members & 74 \\
Non active members & 67 \\
Publishers & $18.71 \%$ \\
Commentors & $36.69 \%$ \\
Likers & $44.6 \%$ \\
\hline
\end{tabular}

Table 8. Type of Posts

\begin{tabular}{ll}
\hline Type of Post & Percentage \\
\hline Course / Content based & $55 \%$ \\
Motivational & $19 \%$ \\
Announcements & $5 \%$ \\
General Discussion & $21 \%$ \\
\hline
\end{tabular}

Table 9. Post Engagement Rate

\begin{tabular}{ll}
\hline Post engagement & Rate $\%$ \\
\hline posts liked and commented & 94.52 \\
posts liked & 75.34 \\
posts commented & 76.71 \\
\hline
\end{tabular}

Table 10. Group Comments Statistics

\begin{tabular}{ll}
\hline Group comments statistics & Count \\
\hline Comment Likes & 37 \\
average comments per post & 8 \\
average words per comment & 10 \\
Average response time & 8 hours \\
Average conversation duration & 53 hours \\
\hline
\end{tabular}




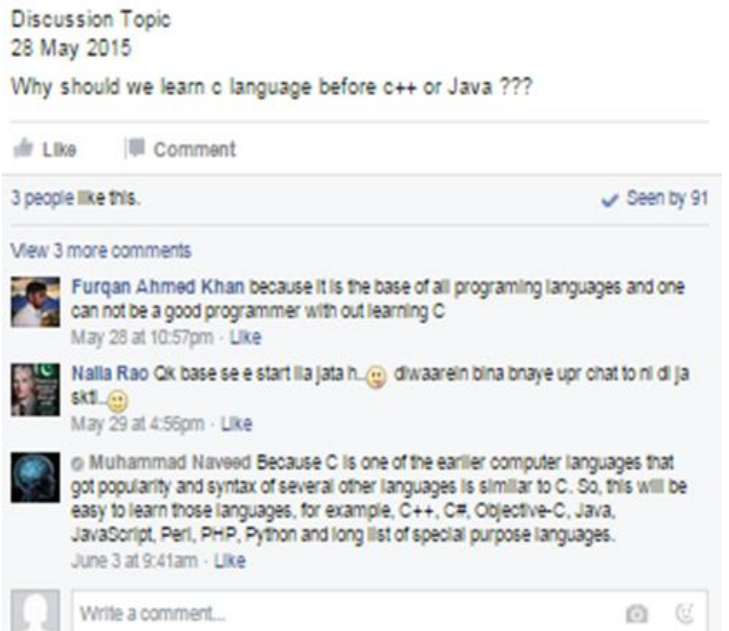

Fig. 2. (a) Example of Discussion Topic; (b) Example of Quiz

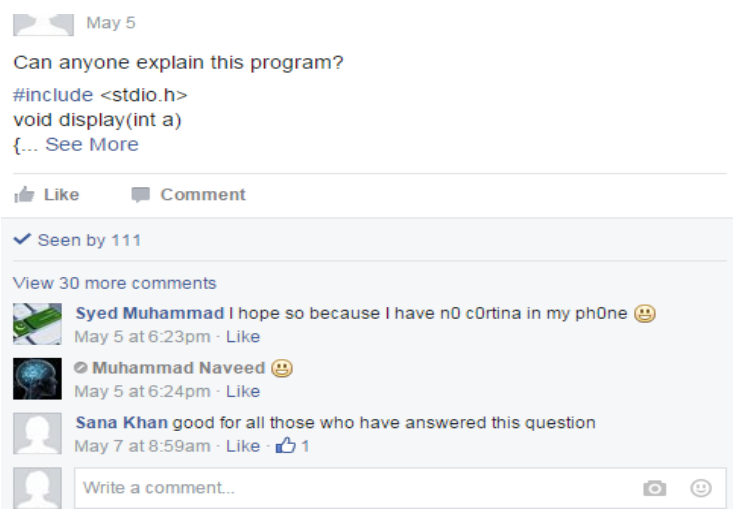

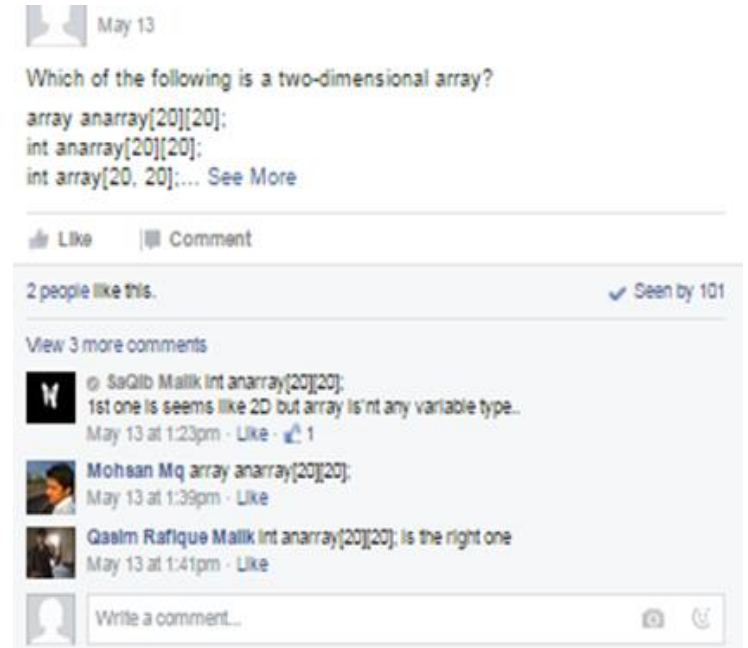

Fig. 3. (a) Example of code Details; (b) Example of Code Output

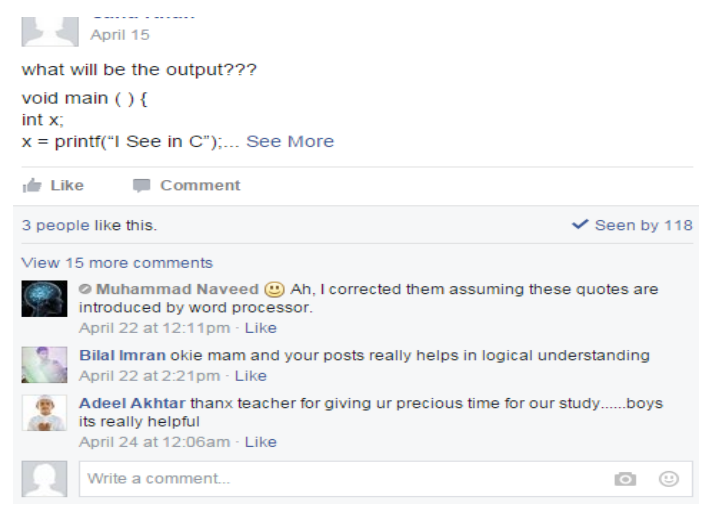

\section{Conclusion and Future Work}

Results of this study indicate that there exists a motivation to use Facebook as more than a social networking website in e-learning by students and faculty. Moreover there is also a positive response to use Facebook to enhance online discussions and interaction among students and faculty. This motivation and interaction can facilitate teaching and learning specifically in the domain of e-learning, where students feel isolated because of lack of communication and collaboration with other students and tutor. Although the participation rate at the Facebook page was low but the rate of likes and comments for course related and motivational based posts in the short time span show that if use properly and effectively, this percentage can definitely be improved to benefit the tertiary education institutes offering e-learning. Participation of novice programmers in Facebook group is quite optimistic to exploit its benefits for teaching and learning process in an e-learning scenario.

Future work is to explore the reasons students don't participate on subject based Facebook page or group and whether only those students who are usually active in normal classroom are active on Facebook. Also the 
comparison of male and female students' participation and interest in subject based Facebook pages and groups needs to be determined.

\section{References}

[1] Yadav, A., \& Jain, S. (2011) Analyses of web usage mining techniques to enhance the capabilities of Elearning environment. In Emerging Trends in Networks and Computer Communications (ETNCC), International Conference on (pp. 223-225), IEEE.

[2] Ali, S. H. S., Azmanuddin, N. S., Ali, W. Z. W., Ayub, A. F. M., \& Adullah, R. (2011, July). Collaboration technology for distance learners: A needs analysis. In Information Technology in Asia (CITA 11), 7th International Conference on (pp. 1-5). IEEE.

[3] Roreger, H., \& Schmidt, T. C. (2012, March). Socialize online learning: Why we should integrate learning content management with Online Social Networks. In Pervasive Computing and Communications Workshops (PERCOM Workshops), International Conference on (pp. 685-690). IEEE.

[4] Musbahtiti, K., Saady, M. R., \& Muhammad, A. (2013, March). Comprehensive e-Learning system based on Islamic principles. In Information and Communication Technology for the Muslim World (ICT4M), 5th International Conference on (pp. 1-5). IEEE.

[5] Chen, Y. C. (2011, July). Learning styles and adopting Facebook technology. InTechnology Management in the Energy Smart World (PICMET), Proceedings of PICMET'11: (pp. 1-9). IEEE.

[6] Li, X., Ganeshan, K., \& Xu, G. (2012, October). The Role of Social Networking Sites in E-learning. In 2012 Frontiers in Education Conference Proceedings (pp. 1-6). IEEE.

[7] Ractham, P., \& Firpo, D. (2011, January). Using social networking technology to enhance learning in higher education: A case study using Facebook. In System Sciences (HICSS), 2011 44th Hawaii International Conference on (pp. 1-10). IEEE.

[8] Silius, K., Miilumaki, T., Huhtamaki, J., Tebest, T., Merilainen, J., \& Pohjolainen, S. (2010, April). Social media enhanced studying and learning in higher education. In Education Engineering (EDUCON), 2010 IEEE (pp. 137-143). IEEE.

[9] Tess, P. A. (2013). The role of social media in higher education classes (real and virtual)-A literature review. Computers in Human Behavior.

[10] Karpinski, A. C., Kirschner, P. A., Ozer, I., Mellott, J. A., \& Ochwo, P. (2012). An exploration of social networking site use, multitasking, and academic performance among United States and European university students. Computers in Human Behavior.

[11] Roreger, H., \& Schmidt, T. C. (2012, March). Socialize online learning: Why we should integrate learning content management with Online Social Networks. In Pervasive Computing and Communications Workshops (PERCOM Workshops), 2012 IEEE International Conference on (pp. 685-690). IEEE.

[12] Ng, E. M., \& Wong, H. C. (2013). Facebook: More than Social Networking for at-risk Students. Procedia-Social and Behavioral Sciences, 73, 22-29.

[13] Deng, L., \& Tavares, N. J. (2013). From Moodle to Facebook: Exploring students' motivation and experiences in online communities. Computers \& Education.

[14] Junco, R. (2012). The relationship between frequency of Facebook use, participation in Facebook activities, and student engagement. Computers \& Education, 58(1), 162-171.

[15] Omar, H., Embi, M. A., \& Yunus, M. M. (2012). Learners' use of Communication Strategies in an Online Discussion via Facebook. Procedia-Social and Behavioral Sciences, 64, 535-544.

[16] İşman, A., \& Ucun, K. (2012). Objectives of the Students Use General and Vocational Education Students to Facebook. Procedia-Social and Behavioral Sciences, 55, 1-10.

[17] Sánchez, R. A., Cortijo, V., \& Javed, U. (2013). Students' Perceptions of Facebook for Academic Purposes. Computers \& Education.

[18] Roblyer, M. D., McDaniel, M., Webb, M., Herman, J., \& Witty, J. V. (2010). Findings on Facebook in 
higher education: A comparison of college faculty and student uses and perceptions of social networking sites. The Internet and Higher Education, 13(3), 134-140.

[19] Hew, K. F. (2011). Students' and teachers' use of Facebook. Computers in Human Behavior, 27(2), 662676.

[20] Rodgers, T. (2008). Student engagement in the e-Learning process and the impact on their grades. International Journal of Cyber Society and Education, 1(2), 143-156.

[21] Nemec, L., Holbl, M., Burkeljca, J., \& Welzer, T. (2011, June). Facebook as a teaching tool. In Eaeeie Annual Conference (Eaeeie), Proceedings of the 22nd (pp. 1-4). IEEE.

[22] Ventura, R., \& Quero, M. J. (2013). Using Facebook in University Teaching: A Practical Case Study. Procedia-Social and Behavioral Sciences, 83, 1032-1038.

[23] Madge, C., Meek, J., Wellens, J., \& Hooley, T. (2009). Facebook, social integration and informal learning at university: It is more for socializing and talking to friends about work than for actually doing work. Learning, Media and Technology, 34(2), $141-155$.

[24] Dabner, N. (2012). "Breaking Ground" in the use of social media: A case study of a university earthquake response to inform educational design with Facebook. Internet and Higher Education, 15(1), 69 - 78.

[25] Irwin, C., Ball, L., Desbrow, B., \& Leveritt, M. (2012). Students' perceptions of using Facebook as an interactive learning resource at university. Australasian Journal of Educational Technology, 28 (7), 1221 $-1232$.

[26] Yu, A. Y, Tian, S. W., Vogel, D., \& Kwok, R. C. W. (2010). Can learning be virtually boosted? An investigation of online social networking impacts. Computers \& Education, 55(4), 1494 - 1503.

[27] Wang, S. L., \& Wu, P. Y. (2008). The role of feedback and self-efficacy on web-based Learning: the social cognitive perspective. Computers \& Education, 51(4), 1589 - 1598.

[28] LaRue, E. M. (2012). Using Facebook as course management software: a case study. Teaching and learning in nursing, 7(1), 17-22.

[29] Din, N., Yahya, S., \& Haron, S. (2012). Information Retrieval and Academic Performance among Facebook Users. Procedia-Social and Behavioral Sciences, 68, 258-268.

[30] Ractham, P., \& Firpo, D. (2011, January). Using social networking technology to enhance learning in higher education: A case study using Facebook. In System Sciences (HICSS), 44th Hawaii International Conference on (pp. 1-10). IEEE.

[31] Kio, S. L., \& Negreiros, J. (2013, March). Facebook as an Informal Learning Space Channel: The São José, Macao Cases. In Learning and Teaching in Computing and Engineering (LaTiCE), on (pp. 70-76). IEEE.

[32] Kaeomanee, Y., Dominic, P., \& Binti Mohd Rias, R. P. (2012, June). Social software enhanced e-learning system to support knowledge sharing among students: Malaysian Higher Education Institutions Perspectives. In Computer \& Information Science (ICCIS), 2012 International Conference on (Vol. 1, pp. 25-30). IEEE.

[33] Varol, A, Ahmed, N., (2013, Oct). Social networks' role in online education. In $7^{\text {th }}$ International Conference on Application of Information and Communication Technologies (AICT), on (pp. 1-4).

[34] Dahroug, A., Abo-Rizka, M., \& Hegazy, A. E. F. (2015, May). The impact of social media networks on enhancing student's performance in online learning systems. In Innovative Computing Technology (INTECH), 2015 Fifth International Conference on (pp. 27-33). IEEE.

[35] Gomes, L. M., Guerra, H., Mendes, A., \& Rego, I. E. (2015, June). Facebook vs moodle: Surveying university students on the use of learning management systems to support learning activities outside the classroom. In Information Systems and Technologies (CISTI), 2015 10th Iberian Conference on (pp. 1-4). IEEE.

[36] Khatoon, M., \& Banu, W. A. (2015). A Survey on Community Detection Methods in Social Networks, International Journal of Education and Management Engineering, 2015, 1, 8-18.

[37] Maleko, M., Hamilton, M. C., D'Souza, D., \& Scholer, F. (2014, April). Understanding and Analysing Novice Programmer Interactions in a Facebook Programming Group. In Teaching and Learning in 
Computing and Engineering (LaTiCE), 2014 International Conference on (pp. 112-119). IEEE.

[38] Ahmed, A., Khan, A. R., \& Ahmed, S. (2014, August). Collaboration of Knowledge Network and ELearning System with Social Sites for Teaching-Learning. In Advances in Computing and Communications (ICACC), 2014 Fourth International Conference on (pp. 147-150). IEEE.

[39] Azeta, A. A., Eweoya, I. O., \& Ojumah, S. (2014, October). Enhancing educational learning with social network platform. In Adaptive Science \& Technology (ICAST), 2014 IEEE 6th International Conference on (pp. 1-4). IEEE.

\section{Authors' Profiles}

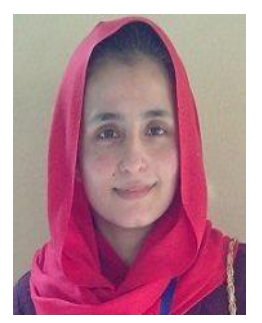

Sana Khan is serving in Computer Science department of COMSATS institute of Information Technology Virtual Campus since March 2013. Her research focus is mainly in the area of e-learning and social networking. She has received the MS degree in Computer Science from COMSATS Institute of Information Technology, Abbottabad, Pakistan in 2008.

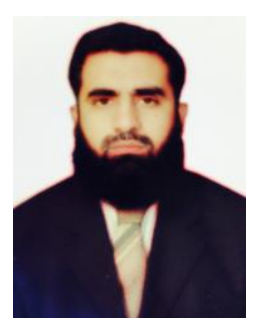

Dr. Sheikh Tahir Bakhsh has been bestowed upon by Gold Medal by the Rector COMSATS Institute of Information Technology, Abbottabad, Pakistan for securing $1^{\text {st }}$ position in MCS in August 2006. Dr. Tahir has received the Ph.D. degree in Computer and Information Sciences from Universiti Teknologi PETRONAS, Malaysia in 2012. He joined the faculty of Computing and Information Technology, King Abdul Aziz University, Saudi Arabia as an Assistant professor in 2013. In the recent he has completed LTE HICI project with the collaboration of Stanford. He has also directed graduate and undergrad graduate projects. His areas of reach interests include Bluetooth network, Wireless sensor network (WSN), Mobile ad hoc network (MANET), and Computer networks. He works mainly on wireless network protocol designs optimizing the performance of networks. Recently, he has been involved in project related physical protocol design for Bluetooth scatternet. He has published more than 25 journal articles and referred conference papers in these areas.

How to cite this paper: Sana Khan, Sheikh Tahir Bakhsh,"A Study on the Role of Facebook in E-Learning", International Journal of Education and Management Engineering(IJEME), Vol.5, No.5, pp.1-11, 2015.DOI: 10.5815/ijeme.2015.05.01 